\title{
Short-term impact of COVID-19 infection on right ventricular functions: single center observational study
}

\author{
Osama Rifaie ${ }^{1}$, Ahmed Reda ${ }^{1}$, Ahmed Hatata' ${ }^{1}$ Amr Gamal ${ }^{1}$ and Mostafa Abdelmonaem ${ }^{1,2^{*}(\text { C) }}$
}

\begin{abstract}
Background: COVID-19 pandemic is associated with high morbidity and mortality. Cardiovascular insult is a leading cause of in-hospital mortality in COVID-19 patients, especially right ventricular (RV) dysfunction and massive pulmonary embolism. This study aims to assess short-term impact of COVID 19 infection on (RV) functions among hospitalized patients with moderate or severe illness using bed side trans-thoracic echocardiogram. This study was conducted in 3 isolation hospitals in Cairo, spanning over 3 months during the expected pandemic peak in Egypt in 2020. The study recruited 100 consecutive patients with moderate or severe COVID-19 infection. Four patients refused to participate in the study. Patients with pre-existing structural heart diseases were excluded. All patients underwent full history taking and clinical examination. Bed side echocardiography was done emphasizing on (RV), and (RA) dimensions, (LV) functions and pulmonary artery systolic pressure (PSAS). Cardiac biomarkers were withdrawn and CT angiography was ordered when clinically warranted.

Results: The mean age of the studied cohort was $59.5 \pm 8.6$ years with males comprising $71.9 \%$ of the studied group. (RV) and (RA) dilatation was noted in 8 cases (8.3\%). (LV) dysfunction was noted in 11 cases (11.4\%). (PASP) showed a statistically significant negative correlation with (LV) function. However, (PSAP) was positively correlated to (RA) and (RV) dimensions, tricuspid regurgitation (TR) jet severity, previous COVID infection and elevated cardiac biomarkers. Mortality was noted in 3 cases (3.1\%), all had LV dysfunction with elevated troponin level. Six patients (6.2\%) had combined (LV) and (RV) dysfunction.

Conclusions: COVID-19 illness had a negative impact on (RV) and (LV) functions, that could be assessed accurately by trans-thoracic $2 \mathrm{D}$ echocardiogram. The degree of ventricular dysfunction correlated with the rise in cardiac biomarkers as well as the degree of (PASP).
\end{abstract}

Keywords: COVID-19, Right ventricle, Pulmonary artery

\section{Background}

COVID-19 pandemic, proved to be caused by acute respiratory syndrome-coronavirus 2-(SARS-COV-2), was the direct cause of millions of mortalities and morbidities

\footnotetext{
*Correspondence: mostafaabdelmonaem@yahoo.com

${ }^{1}$ Department of Cardiology, Faculty of Medicine, Ain Shams University, Cairo, Egypt

Full list of author information is available at the end of the article No relationship with industry exist for any of the above-mentioned authors
}

all over the globe. This viral infection was accused of multi-organ dysfunction, beside a variety of post-survival handicapping sequelae. Acute cardiac complications were the mean reason of in-hospital mortality, including; acute myocardial infarction, life threatening arrythmia, cardiac tamponade, fulminant myocarditis, pulmonary embolism and right ventricular dysfunction [1-4].

A report from Wuhan, China, reported that $12 \%$ of 41 patients hospitalized with COVID-19, had signs of cardiovascular involvement as diagnosed by elevated troponin associated with ECG and echocardiographic 
abnormalities. Since then, other reports have affirmed that cardiac injury can be a part of Corona virus injury $[4,5]$.

Previous researches focused on biomarkers of myocardial injury as predictors of in-hospital adverse events in COVID-19 patients as high sensitive Troponin and D-dimer. Other preliminary data considered imaging modalities promising tools to predict cardiac events beside its pivotal role in declaring the underling mechanism of cardiovascular complications [6-9].

Provided the clinical relevance of right ventricular involvement in acute respiratory illness and ARDS, 2D trans-thoracic echocardiogram is recommended to evaluate right heart functions among COVID-19 illness as stated by the American society of echocardiography and European Association of cardiovascular imaging (EACVI) [10-14].

Two dimensional echocardiogram provides simple, fast and reliable bed side test to assess cardiac functions and COVID-19 related cardiovascular complications in patients with hemodynamic instability. For issues concerning infection control, routine bed side echo is not recommended for every admitted patient with COVID19 [15].

\section{Aim of the work}

To assess short-term impact of COVID-19 infection on right ventricular function among hospitalized patients with moderate or severe illness using bed side trans-thoracic echocardiogram.

\section{Methods}

\section{Study population}

Single center observational study conducted in university isolation hospitals. Patients recruitment spanned over 4 months from November 2020 to the end of February 2021 aiming to cover the expected Pandemic peak among Egyptians. One hundred admitted patients were eligible for participation in this study, four patients waived participation, so 96 COVID-19 patients were finally incorporated. A written and informed consent was obtained from every patient. The Study was approved by the Ethic Committee of scientific research.

This study included all admitted patients over 18 years old with moderate or severe COVID-19 infection who accepted to participate in this research. We excluded patients refusing participation and those with pre-existing structural heart diseases.

\section{Methods}

All patients were subjected to the following: A full detailed history including demographic data as age, gender, presence of risk factors as hypertension, diabetes mellitus, dyslipidaemia and smoking. Previous Myocardial infarction and revascularization, rheumatic cardiac affection, arrhythmogenic heart disease, and structural heart disease were also mentioned and considered as exclusion criteria.

All patients underwent a full detailed ECG gated transthoracic echocardiographic study using GE VIVID S 6 apparatus. All operators wore full PPIs. An Echocardiogram was done in left lateral position using apical and parasternal views. The study included detection and quantification of valvular affection (using $2 \mathrm{D}$, and colour Doppler), evaluation of LV diameters and volumes, segmental wall motion, diastolic function and ejection fraction using $M$ mode and 2D. Assessment of aortic root and left atrial diameters and volume. Evaluation of RV, RA size, RV systolic functions and tricuspid annular plane systolic excursion (TAPSE), right ventricular systolic pressure in $\mathrm{mmHg}$. Evaluation of the pericardium and quantification of pericardial effusion if present. Tissue Doppler assessment of mitral and tricuspid annuli. All echocardiogram reports comply with recommendations of the European society of echocardiography [14]. All saved loops and images were revised by two independent expert interpreters who were blinded about the patient's clinical data. After each study, the echocardiogram probe was cleaned using hydrogen peroxide disposable wipes. It is worth-mentioning that once echocardiogram was used in COVID-19 isolation zone, it remained in service in this zone and not allowed to be shared by other departments.

\section{Statistical analysis}

Statistical tests were selected and applied according to type of data collected. For qualitative data, frequency and relative frequency, the chi-square was used for analysis. Quantitative variables were expressed as mean \pm SD. An independent sample $t$-test analysis was used for the statistical analysis of the continuous data. Univariate then multivariate logistic regression were done to correlate different parameters affecting PASP, Significance was evaluated at $p<0.05$ levels. The statistical analysis was conducted using the Statistical Package for Social Science (SPSS software version 22).

\section{Results}

\section{Demographic data and risk factors:}

This study included 96 patients with confirmed COVID19 infection. Mean age of the studied cohort was $59.5 \pm 8.63$ years with males comprising $71.9 \%$ of studied population. $73 \%$ of patients were active smokers and only $2 \%$ had preexisting chest morbidity (Table 1 ).

Regarding CT chest on admission, 64 patients had chest findings of CORAD 5, 20 patients had CORAD 4 and 12 had CORAD 3 with a positive PCR test of 
Table 1 Demographic data of studied population

\begin{tabular}{ll}
\hline & $\mathbf{N o}=\mathbf{9 6}$ \\
\hline $\begin{array}{l}\text { Age (years) } \\
\text { Mean } \pm \text { SD }\end{array}$ & $59.58 \pm 8.63$ \\
Range & $34-77$ \\
Gender & \\
Female & $27(28.1 \%)$ \\
Male & $69(71.9 \%)$ \\
Smokers & \\
No & $26(27.1 \%)$ \\
Yes & $70(72.9 \%)$ \\
Pre-existing chest disease & \\
No & $94(97.9 \%)$ \\
Yes & $2(2.1 \%)$ \\
\hline
\end{tabular}

COVID-19 infection. Four patients were previous survivors of COVID-19. Median CRP was $25 \mathrm{mg} / \mathrm{l}$ ranging between 10 and $110 \mathrm{mg} / \mathrm{l}$. All recruited patients had no past history of pre-existing structural heart disease, however during admission, 11 patients showed impaired LV systolic functions (11.3\%). Baseline highly sensitive troponin was withdrawn for all subjects, results were positive in $85.4 \%$ of patients with moderate to severe illness.

Baseline echocardiographic study revealed; dilated RA dimensions in $8.3 \%$ of patients, mean RV base diameter of $36 \mathrm{~mm}$ and ranging from 32 to $48 \mathrm{~mm}$, mean TAPSE $19.7 \mathrm{~mm}$ ranging from 14 to $28 \mathrm{~mm}$. $7.3 \%$ of patients had severe tricuspid incompetence and mean RVSP was $36 \mathrm{mmHg}$ ranging from 20 to $65 \mathrm{mmHg}$ (Table 2). CT pulmonary angiography was ordered in patients highly suspected of pulmonary emboli and 10 patients were diagnosed during hospital stay with pulmonary embolism, four of them necessitated thrombolytic therapy.

Regarding hospital course, 93 patients were discharged to home in fair condition and unfortunately, 3 patients died during hospital stay from COVID-19 systemic complications.

\section{Factors influencing pulmonary artery pressure (Table 3)}

Gender difference and age did not show any statistical relation to pulmonary artery pressure, smokers had numerically higher pulmonary artery pressure with no statistical significance. The severity of right atrial dimensions and jet of tricuspid incompetence were statistically correlated to pulmonary systolic pressure. Survivors of previous COVID-19 infections had statistically relevant higher PASP as compared to other patients with de novo COVID-19 infection. Troponin and creatinine kinase showed a highly significant relationship with PASP with $p$ value of 0.0001 . De novo decline in LV systolic functions showed a high statistical relation to PASP with $p$ value of 0.0001 .
Table 2 Baseline investigation and laboratory work up on admission

\begin{tabular}{|c|c|}
\hline & $\mathrm{No}=96$ \\
\hline \multicolumn{2}{|l|}{ CTCHEST } \\
\hline CORAD 3 & $12(12.5 \%)$ \\
\hline CORAD 4 & $20(20.8 \%)$ \\
\hline CORAD 5 & $64(66.7 \%)$ \\
\hline \multicolumn{2}{|c|}{ CT pulmonary angiogram proven pulmonary embolism } \\
\hline No & $86(89.6 \%)$ \\
\hline Yes & $10(10.4 \%)$ \\
\hline \multicolumn{2}{|l|}{$\mathrm{TLC} / \mathrm{cmm}$} \\
\hline Mean $\pm S D$ & $16.90 \pm 3.76$ \\
\hline Range & $11-30$ \\
\hline \multicolumn{2}{|l|}{ Serum ferritin } \\
\hline High & $96(100.0 \%)$ \\
\hline \multicolumn{2}{|l|}{ CRP mg/l } \\
\hline Median(IQR) & $25(20.5-32.5)$ \\
\hline Range & $10-110$ \\
\hline \multicolumn{2}{|l|}{ ESRmm 1sth } \\
\hline Median(IQR) & $32(23-43.5)$ \\
\hline Range & $10-102$ \\
\hline \multicolumn{2}{|l|}{ RV Base dimensions mm } \\
\hline Mean \pm SD & $36.44 \pm 3.18$ \\
\hline Range & $32-48$ \\
\hline \multicolumn{2}{|l|}{$R A$} \\
\hline Normal & $88(91.7 \%)$ \\
\hline Dilated & $8(8.3 \%)$ \\
\hline \multicolumn{2}{|l|}{ TAPSE $\mathrm{mm}$} \\
\hline Mean \pm SD & $19.71 \pm 2.35$ \\
\hline Range & $14-28$ \\
\hline \multicolumn{2}{|l|}{ TRJET } \\
\hline Moderate & $59(61.5 \%)$ \\
\hline Mild & $30(31.2 \%)$ \\
\hline Severe & $7(7.3 \%)$ \\
\hline \multicolumn{2}{|l|}{$\operatorname{RVSP}(m m H g)$} \\
\hline Mean \pm SD & $36.34 \pm 8.62$ \\
\hline Range & $20-65$ \\
\hline \multicolumn{2}{|l|}{ RVSP groups } \\
\hline Normal RVSP & $26(27.1 \%)$ \\
\hline High RVSP ( $\geq 35 \mathrm{mmhg}$ ) & $70(72.9 \%)$ \\
\hline \multicolumn{2}{|l|}{ PREVIOUS COVID INEFCTION } \\
\hline No & $92(95.8 \%)$ \\
\hline Yes & $4(4.2 \%)$ \\
\hline \multicolumn{2}{|l|}{ Mortality } \\
\hline No & 93 (96.9\%) \\
\hline Yes & $3(3.1 \%)$ \\
\hline \multicolumn{2}{|l|}{ Troponin and CK } \\
\hline Positive & $82(85.4 \%)$ \\
\hline Negative & $14(14.6 \%)$ \\
\hline \multicolumn{2}{|l|}{ LV systolic function } \\
\hline Normal (EF $\geq 50 \%)$ & 85 (88.5\%) \\
\hline Impaired & $11(11.5 \%)$ \\
\hline
\end{tabular}


Table 3 Factors influencing pulmonary artery pressure

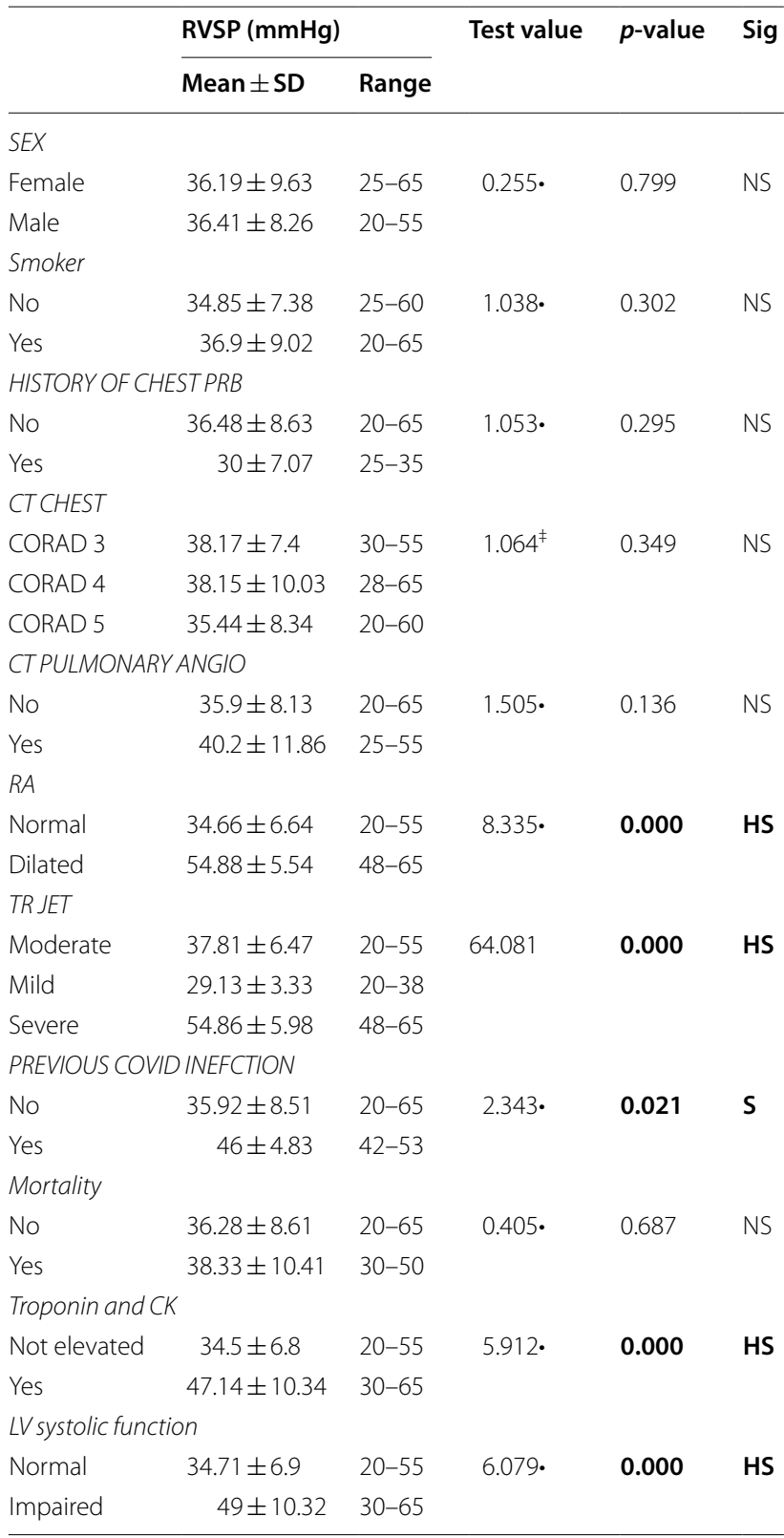

Bold indicates highly significant

$\because$ Independent t-test; $¥:$ One Way ANOVA test

Table 4 shows the results of univariate analysis to correlate different parameters affecting PASP, the only significant predictor was right ventricular basal diameter (Fig. 1).

Patients were divided to 2 groups according to RVSP; group with normal RVSP (26 patients) and another group with high RVSP exceeding $35 \mathrm{mmHg}$ (70 patients). Severity of TR jet and right ventricular basal dimensions showed statistically significant relation to group with
Table 4 Logistic regression analysis of factors influencing RVSP,

\begin{tabular}{lcl}
\hline & \multicolumn{2}{l}{ RVSP $(\mathbf{m m H g})$} \\
\cline { 2 - 3 } & $\boldsymbol{r}$ & $\boldsymbol{p}$-value \\
\hline AGE & -0.095 & 0.355 \\
TLC (thousands) & 0.199 & 0.052 \\
CRP & 0.025 & 0.809 \\
ESR & -0.041 & 0.693 \\
RV BASE & $\mathbf{0 . 3 0 9 ^ { * * }}$ & $\mathbf{0 . 0 0 2}$ \\
TAPSE & -0.043 & 0.680 \\
\hline
\end{tabular}

Bold indicates highly significant

$r=$ Spearman correlation coefficients $* *=$ Significant $p$ value

high RVSP with $p$ value of 0.00 and 0.04 , respectively (Table 5).

\section{Discussion}

It is understood that severe COVID-19 infection causes multi-organ dysfunction, and cardiac injury yields worse outcomes [16]. Trans-thoracic echocardiography is helpful in this group of patients but not routinely ordered to minimize the risk of disease transmission [17]. It enables bed side and non-invasive assessment of heart function and hemodynamic status of the patient [16]. Conventional echocardiography study can rule out obstructive problems (e.g., cardiac tamponade and pulmonary embolism) and hypovolemic shock (decreased cardiac output and collapsed IVC) [17-20]. In recent years, many studies observed that nearly $40 \%$ of severe sepsis patients developed a decline in left ventricular systolic and diastolic functions. In severe sepsis hyperdynamic status increases cardiac performance due to systemic inflammatory response. In later stages, hypoxia and inflammation cause myocardial suppression [20].

The main finding of this study was that COVID-19 negatively affects the RV as well as LV functions. Moreover, we found a strong correlation between right ventricular systolic pressure and elevated cardiac biomarkers, right ventricular dimensions as well as with newly recognized left ventricular systolic dysfunction. This finding confirmed the injurious effect of COVID-19 infection on myocardial performance. COVID-19 myocardial impact is not only on pulmonary artery pressure and right ventricular dimensions but also it harms left ventricular systolic functions which were directly correlated to high recording of right ventricular systolic pressure. The magnitude of rise of cardiac biomarkers was correlated to high right ventricular systolic pressure assessed by echocardiography, supporting the hypothesis of using either cardiac biomarkers or bed side imaging to predict right ventricular injury and consequently predicting worse outcome during hospital stay. In fact, the 3 patients who 


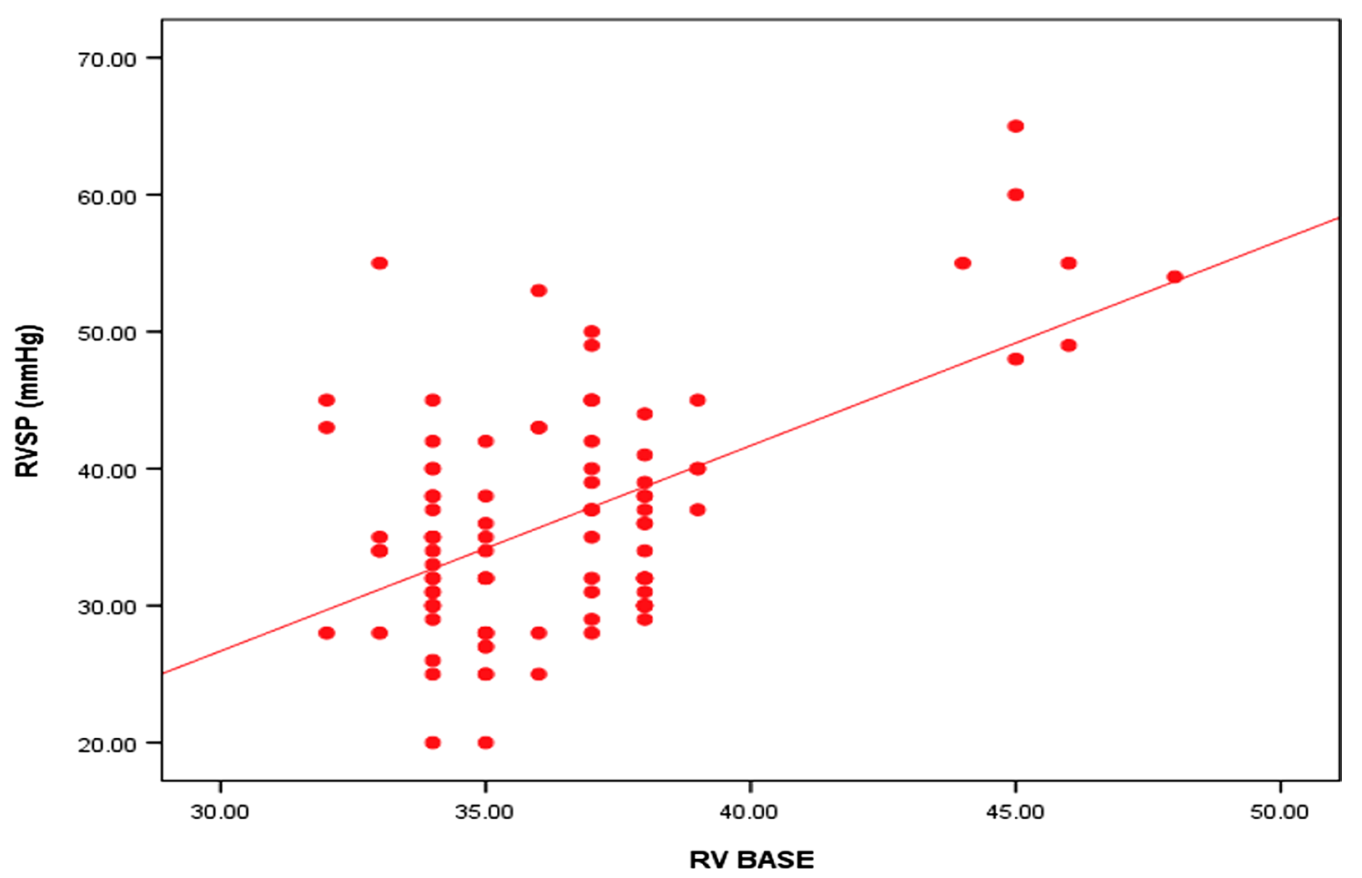

Fig. 1 Spearman correlation between RVSP and RV base diameter

died in this study had LV dysfunction and elevated Troponin serum level. Patients with previous COVID-19 infection who were re-admitted by moderate or severe infection were more liable for de novo myocardial injury in terms of elevated pulmonary artery pressure.

These findings were in accordance with Barman et al. who showed a statistically positive correlation between RV diameter and troponin level, similarly left ventricular systolic functions showed a statistically significant negative correlation with troponin and RV systolic functions. In their linear regression model; Troponin, left ventricular ejection fraction, D-dimer, RA dimensions and PASP were independent predictors of RV dilatation [21].

Further evidence of RV involvement in COVID-19 was mentioned by D'Andrea et al., who reported a statistically significant association between RV dilation/ systolic dysfunction and mortality in a cohort of 115 patients. Patients with RV dysfunction had signs of myocardial injury (elevated Troponin), more severe lung disease, and higher pulmonary artery pressure, suggesting increased afterload as the primary mechanism of RV dysfunction in patients with severe COVID-19 sepsis [22]. In line with these findings, Kim et al. released data from 510 patients who underwent echocardiography in three NY hospitals from March to May 2020 [20]. RV dilation was detected in $35 \%$ of the cohort, while RV systolic dysfunction was found in $15 \%$. These changes were associated with higher levels of circulating biomarkers.
RV abnormalities were associated with lower LVEF, and associated with higher pulmonary artery systolic pressure, supporting an increased pulmonary vascular load as the primary pathophysiological mechanism. In multivariate analysis, RV abnormalities independently predicted mortality (32\% of the cohort) [23].

In this study, TAPSE as a marker of RV systolic functions did not show a statistically relevant correlation to PASP, despite the strong correlation between RV basal dimensions and PASP. This finding could be attributed to the diversity of factors influencing TAPSE measurements as LV systolic functions, ischemic etiology of heart failure and wall motion index of RV [24]. Another point, is the impact of TR jet severity on reproducibility of TAPSE, severe TR is a confounding factor when TAPSE is used to assess RV systolic functions [25].

Despite the crucial rule of bed side echocardiogram in evaluating RT ventricular functions and its impact in predicting patient course during his hospital stay, the decision to perform echocardiogram should be only when clinically warranted and with the use of full personal protective equipments to minimize virus transmission. Moreover, the need for follow up study for a COVID-19 patient should be based upon multidisciplinary treating team since the effect of COVID19 on ventricular function might be extended to longer periods. 
Table 5 Comparison between patients with normal and high RVSP

\begin{tabular}{|c|c|c|c|c|c|}
\hline & $\begin{array}{l}\text { Normal RVSP } \\
(31.2 \pm 3.1) \\
\text { No. }=26\end{array}$ & $\begin{array}{l}\text { High RVSP } \\
(45 \pm 10.3) \\
\text { No. }=70\end{array}$ & Test value & $p$-value & Sig \\
\hline \multicolumn{6}{|l|}{$A G E$} \\
\hline Mean $\pm S D$ & $61.12 \pm 9.95$ & $59.01 \pm 8.09$ & $1.061 \bullet$ & 0.291 & NS \\
\hline Range & $34-76$ & $38-77$ & & & \\
\hline \multicolumn{6}{|l|}{ SEX } \\
\hline Female & $8(30.8 \%)$ & $19(27.1 \%)$ & $0.123^{*}$ & 0.725 & NS \\
\hline Male & $18(69.2 \%)$ & $51(72.9 \%)$ & & & \\
\hline \multicolumn{6}{|l|}{ SMOEKR } \\
\hline No & $7(26.9 \%)$ & $19(27.1 \%)$ & $0.000^{*}$ & 0.983 & NS \\
\hline Yes & $19(73.1 \%)$ & $51(72.9 \%)$ & & & \\
\hline \multicolumn{6}{|c|}{ HISTORY OF CHEST PRB } \\
\hline No & $25(96.2 \%)$ & $69(98.6 \%)$ & $0.543^{*}$ & 0.461 & NS \\
\hline Yes & $1(3.8 \%)$ & $1(1.4 \%)$ & & & \\
\hline \multicolumn{6}{|l|}{ CT CHEST } \\
\hline CORAD 3 & $2(7.7 \%)$ & $10(14.3 \%)$ & $0.923^{*}$ & 0.630 & NS \\
\hline CORAD 4 & $5(19.2 \%)$ & $15(21.4 \%)$ & & & \\
\hline CORAD 5 & $19(73.1 \%)$ & $45(64.3 \%)$ & & & \\
\hline \multicolumn{6}{|c|}{ CTPULMONARY ANGIO } \\
\hline No & $22(84.6 \%)$ & $64(91.4 \%)$ & $0.943^{*}$ & 0.331 & NS \\
\hline Yes & $4(15.4 \%)$ & $6(8.6 \%)$ & & & \\
\hline \multicolumn{6}{|l|}{ RA } \\
\hline Normal & $26(100.0 \%)$ & $62(88.6 \%)$ & $3.242^{*}$ & 0.072 & NS \\
\hline Dilated & $0(0.0 \%)$ & $8(11.4 \%)$ & & & \\
\hline \multicolumn{6}{|l|}{ TR JET } \\
\hline Moderate & $5(19.2 \%)$ & $54(77.1 \%)$ & $40.925^{*}$ & 0.000 & HS \\
\hline Mild & $21(80.8 \%)$ & $9(12.9 \%)$ & & & \\
\hline Severe & $0(0.0 \%)$ & $7(10.0 \%)$ & & & \\
\hline \multicolumn{6}{|c|}{ TLC (thousands) } \\
\hline Mean $\pm S D$ & $15.90 \pm 2.64$ & $17.27 \pm 4.05$ & -1.607 & 0.111 & NS \\
\hline Range & $11-20$ & $11-30$ & & & \\
\hline \multicolumn{6}{|l|}{$C R P$} \\
\hline Median (IQR) & $28.5(22-45)$ & $24.5(20-31)$ & $0.929^{\ddagger}$ & 0.353 & NS \\
\hline Range & $10-110$ & $10-110$ & & & \\
\hline \multicolumn{6}{|l|}{$E S R$} \\
\hline Median (IQR) & $30.5(24-40)$ & $32(22-44)$ & $0.012^{\ddagger}$ & 0.990 & NS \\
\hline Range & $18-102$ & $10-100$ & & & \\
\hline \multicolumn{6}{|l|}{ RVBASE } \\
\hline Mean \pm SD & $35.35 \pm 1.70$ & $36.84 \pm 3.50$ & -2.086 & 0.040 & $S$ \\
\hline Range & $32-38$ & $32-48$ & & & \\
\hline \multicolumn{6}{|l|}{ TAPSE } \\
\hline Mean $\pm S D$ & $19.69 \pm 1.85$ & $19.71 \pm 2.52$ & -0.041 & 0.968 & NS \\
\hline Range & $17-23$ & $14-28$ & & & \\
\hline \multicolumn{6}{|c|}{ PREVIOUS COVID INEFCTION } \\
\hline No & $26(100.0 \%)$ & $66(94.3 \%)$ & $1.550^{*}$ & 0.213 & NS \\
\hline Yes & $0(0.0 \%)$ & $4(5.7 \%)$ & & & \\
\hline \multicolumn{6}{|l|}{ Mortality } \\
\hline No & $25(96.2 \%)$ & $68(97.1 \%)$ & $0.061^{*}$ & 0.805 & NS \\
\hline
\end{tabular}

Table 5 (continued)

\begin{tabular}{|c|c|c|c|c|c|}
\hline & $\begin{array}{l}\text { Normal RVSP } \\
(31.2 \pm 3.1)\end{array}$ & $\begin{array}{l}\text { High RVSP } \\
(45 \pm 10.3)\end{array}$ & Test value & $p$-value & Sig \\
\hline & No. $=26$ & No. $=70$ & & & \\
\hline Yes & $1(3.8 \%)$ & $2(2.9 \%)$ & & & \\
\hline \multicolumn{6}{|c|}{ Troponin and CK } \\
\hline Not elevated & 25 (96.2\%) & $57(81.4 \%)$ & $3.300^{*}$ & 0.069 & NS \\
\hline Yes & $1(3.8 \%)$ & $13(18.6 \%)$ & & & \\
\hline \multicolumn{6}{|c|}{ LV systolic function } \\
\hline Normal & 25 (96.2\%) & $60(85.7 \%)$ & $2.037^{*}$ & 0.154 & NS \\
\hline Impaired & $1(3.8 \%)$ & $10(14.3 \%)$ & & & \\
\hline
\end{tabular}

Bold indicates highly significant

*: Chi-square test; $:$ Independent t-test; $¥:$ Mann-Whitney test

\section{Conclusions}

COVID-19 illness had a negative impact on right ventricular as well as left ventricular functions, which could be assessed accurately by trans-thoracic $2 \mathrm{D}$ echocardiogram. RV dimensions increased with pulmonary artery systolic pressure. The latter matched with the rise in cardiac biomarkers.

\section{Limitation}

This was a single center study with a relatively small sample size. We are in need of multi-center prospective study with long-term follow up to understand COVID-19 illness myocardial injury and propose solutions to minimize patient morbidity and mortality.

\section{Abbreviations \\ RV: Right ventricle; LV: Left ventricle; RVSP: Right ventricular systolic pressure; LVEF: Left ventricular ejection fraction; TR: Tricuspid regurgitation; TAPSE: Tricuspid annular plane systolic excursion; PASP: Pulmonary artery systolic pressure; 2D: Two dimensional.}

\section{Acknowledgements}

Not applicable.

\section{Authors' contributions}

The authors listed below have contributed significantly to the submitted work: MA: Lecturer, has took part in: conception and design of the study, and interpretation of the data, drafting of the manuscript and final approval of the manuscript submitted. OR: Professor of Cardiology, has contributed in conception and design of the study. AR: Lecturer of Cardiology and AH: Assistant Lecturer of Cardiology, contributed in performing echocardiogram studies and data collection. AG: Lecturer of Cardiology, contributed in performing echocardiogram studied and data interpretation. All authors have read and approved the manuscript.

Funding

Not Funded. The studied cohort was recruited from pool of patients referred to Ain Shams university cardiology department catheterization laboratory and echocardiography unit. 


\section{Availability of data and material}

All Data including angiogram films and stored echocardiographic loops are available with the authors and in Ain Shams University echocardiography records.

\section{Declarations}

\section{Ethical approval and consent to participate}

The Research Ethics Committee of the faculty of medicine, Ain Shams University has reviewed and approved the study from the ethical point (FMASU R 190/2021). The faculty of medicine Ain Shams University Research Ethics Committee (REC) is organized and operated according to guidelines of the international council of harmonization $(\mathrm{ICH})$ Anesthesiology and the Islamic organization of medical science (IOMS), the united stated office of human research protection and united states code of federal regulations and operates under federal wide assurance No. FWA 000017585 . The REC does not declare the name of its members according to the university and REC standard operating procedures. The data of patients were presented after informed written consent achievement, and the steps of research were explained for them with the protection of privacy and confidentiality.

\section{Consent of publications}

Not Applicable.

\section{Competing interests}

All authors declare that there are no conflicts of interests.

\section{Author details}

'Department of Cardiology, Faculty of Medicine, Ain Shams University, Cairo, Egypt. ${ }^{2}$ Interventional Cardiology Unit, Cardiology Department, Ain Shams University Hospital, Mohamed Hilal Street Villa 10, Abbassia, Cairo P0 11371, Obour City, Egypt.

Received: 9 December 2021 Accepted: 17 January 2022

Published online: 02 February 2022

\section{References}

1. Feng Y, Ling Y, Bai T, Xie Y, Huang J, Li J et al (2020) COVID 19 with different severity: a multi-center study of clinical feature. Am J Respir Crit Care Med 201:1380-1381

2. World Health Organization (2020) Naming the coronavirus disease (COVID-19) and the virus that causes it. World Health Organization. https://www.who.int/emergencies/diseases/nove/coron avirus-2019/technicalguidance/naming-the-coronavirus-disea se-(covid-2019)-and-the-virus-that-causes-it

3. Akhmerov A, Marbán E (2020) COVID-19 and the heart. Circ Res 126(10):1443-1455

4. Bansal M (2020) Cardiovascular disease and COVID-19. Diab Metab Syndr. https://doi.org/10.1016/j.dsx.2020.03.013

5. Peng Q-Y, Wang X-T, Zhang L-N (2020) Using echocardiography to guide the treatment of novel coronavirus pneumonia. Crit Care. https://doi.org/ 10.1186/s13054-020-02856-Z

6. Argulian E, Sud K, Vogel B et al (2020) Right ventricular dilation in hospitalized patients with COVID-19 infection. JACC Cardio vasc Imaging 13:2459-2461

7. Huang L, Zhao P, Tang D et al (2020) Cardiac involvement in patients recovered from COVID-2019 identifed using magnetic resonance imaging. JACC Cardiovasc Imaging 13:2330-2339

8. Churchill TW, Bertrand PB, Bernard S et al (2020) Echocardiographic features of COVID-19 illness and association with cardiac biomarkers. $J$ Am Soc Echocardiogr 33:1053-1054

9. Mahmoud-Elsayed HM, Moody WE, Bradlow WM et al (2020) Echocardiographic findings in patients with COVID-19 pneumonia. Can J Cardiol 36:1203-1207

10. Creel-Bulos C, Hockstein M, Amin N, Melhem S, Truong A, Sharifpour M (2020) Acute cor pulmonale in critically III patients with Covid-19. N Engl J Med 382:e70
11. Rauch S, Regli IB, Clara A, Seraglio PM, Bock M, Poschenrieder F, Resch M (2020) Right ventricular myopericarditis in COVID-19: a call for regular echocardiography. Minerva Anestesiol 86:1253-1254

12. Ferrante G, Fazzari F, Cozzi O, Maurina M, Bragato R, D'Orazio F, Torrisi C, Lanza E, Indolfi E, Donghi V et al (2020) Risk factors for myocardial injury and death in patients with COVID-19: insights from a cohort study with chest computed tomography. Cardiovasc Res 116:2239-2246

13. Konstam MA, Kiernan MS, Bernstein D, Bozkurt B, Jacob M, Kapur NK, Kociol RD, Lewis EF, Mehra MR, Pagani FD et al (2018) Evaluation and management of right-sided heart failure: a scientific statement from the American Heart Association. Circulation 137:e578-e622

14. García-Cruz E, Manzur-Sandoval D, Baeza-Herrera LA, Díaz-Méndez A, López-Zamora A, González-Ruiz F, Ángel RE, Melano-Carranza E, RojasVelasco G, Álvarez-Álvarez RJ et al (2021) Acute right ventricular failure in COVID-19 infection: a case series. J Cardiol Cases 24:45-48

15. Patel BV, Arachchillage DJ, Ridge CA et al (2020) Pulmonary angiopathy in severe COVID-19: physiologic, imaging, and hematologic observations. Am J Respir Crit Care Med 202:690-699

16. Lippi G, Lavie CJ, Sanchis-Gomar F (2020) Cardiac troponin I in patients with coronavirus disease 2019 (COVID19): evidence from a meta-analysis. Prog Cardiovasc Dis 63:390-391

17. Picard MH, Weiner RB (2020) Echocardiography in the time of COVID-19. J Am Soc Echocardiogr. https://doi.org/10.1016/j.echo.2020.04.011

18. Nagre AS (2019) Focus-assessed transthoracic echocardiography: implications in perioperative and intensive care. Ann Card Anaesth 22(3):302

19. Perera P, Mailhot T, Riley D, Mandavia D (2010) The RUSH exam: rapid ultrasound in shock in the evaluation of the critically III. Emerg Med Clin 28(1):29-56

20. Zhang L-N, Zhang H-M, Cao Y-G, Yin W-H, He W, Zhu R et al (2017) Ten basic principles about critical ultrasonography: critical care practitioners need to know. Chin Med J 130(13):1610

21. Barman HA, Atici A, Tekin EA et al (2020) Echocardiographic features of patients with COVID 19 infection: a cross sectional study. Int J Cardiovasc Imaging. https://doi.org/10.1007/s10554-020-02051-9

22. D'Andrea A, Scarafile R, Riegler L, Liccardo B, Crescibene F, Cocchia R, Bossone E (2020) Right ventricular function and pulmonary pressures as independent predictors of survival in patients with COVID-19 pneumonia. JACC Cardiovasc Imaging 13:2467-2468

23. Kim J, Volodarskiy A, Sultana R, Pollie MP, Yum B, Nambiar L, Tafreshi R, Mit lak HW, RoyChoudhury A, Horn EM et al (2020) Prognostic utility of right ventricular remodeling over conventional risk stratification in patients with COVID-19. J Am Coll Cardiol 76:1965-1977

24. Kjaergaard J, Iversen KK, Akkan D, Møller JE, Køber LV, Torp-Pedersen C, Hassager C (2009) Predictors of right ventricular function as measured by tricuspid annular plane systolic excursion in heart failure. Cardiovasc Ultrasound 7:51

25. Hsiao SH, Lin SK, Wang WC, Yang SH, Gin PL, Liu CP (2006) Severe tricuspid regurgitation shows significant impact in the relationship among peak systolic tricuspid annular velocity, tricuspid annular plane systolic excursion and right ventricular ejection fraction. J Am Soc Echocardiogr 19:902-910

\section{Publisher's Note}

Springer Nature remains neutral with regard to jurisdictional claims in published maps and institutional affiliations. 